\title{
Does radiotherapy increase the risk of colorectal cancer among prostate cancer patients? A large population-based study
}

\author{
Chung-Han Ho ${ }^{1,2,3}$, Kuo-Chen Cheng4,5, Chien-Ming Chao 6,7,8, Chih-Cheng Lai ${ }^{9}$, Shyh-Ren Chiang ${ }^{4,10}$, \\ Chin-Ming Chen7, Kuang-Ming Liao ${ }^{11}$, Jhi-Joung Wang,12, Po-Huang Lee ${ }^{13}$, Chao-Ming Hung14, Chi-Ming \\ Tai ${ }^{15}$, Chong-Chi Chiu ${ }^{14 \bowtie}$ \\ 1. Department of Medical Research, Chi Mei Medical Center, Tainan 71004, Taiwan \\ 2. Department of Hospital and Health Care Administration, Chia Nan University of Pharmacy and Science, Tainan 71710, Taiwan \\ 3. Cancer Center, Wan Fang Hospital, Taipei Medical University, Taipei 11696, Taiwan \\ 4. Department of Internal Medicine, Chi Mei Medical Center, Tainan 71004, Taiwan \\ 5. Department of Safety, Health and Environment, Chung Hwa University of Medical Technology, Tainan 71703, Taiwan \\ 6. Department of Intensive Care Medicine, Chi Mei Medical Center, Liouying 73657, Taiwan \\ 7. Department of Intensive Care Medicine, Chi Mei Medical Center, Tainan 71004, Taiwan \\ 8. Department of Dental Laboratory Technology, Min-Hwei College of Health Care Management, Tainan 73657, Taiwan \\ 9. Department of Internal Medicine, Kaohsiung Veterans General Hospital, Tainan Branch, Tainan 71004, Taiwan \\ 10. Departments of General Education, Chia Nan University of Pharmacy and Science, Tainan 71710, Taiwan \\ 11. Department of Internal Medicine, Chi Mei Medical Center, Chiali 72263, Taiwan. \\ 12. AI Biomed Center, Southern Taiwan University of Science and Technology, Tainan 71005, Taiwan \\ 13. Department of Surgery, E-Da Hospital. I-Shou University, Kaohsiung 82400, Taiwan \\ 14. Department of General Surgery, E-Da Cancer Hospital, I-Shou University, Kaohsiung 82400, Taiwan \\ 15. Department of Internal Medicine, E-Da Hospital, I-Shou University, Kaohsiung 82400, Taiwan
}

$\square$ Corresponding author: Chong-Chi Chiu, MD, Professor, Department of General Surgery, E-Da Cancer Hospital, I-Shou University, Kaohsiung, 82400, Taiwan. Mail address: P. O. Box 174 Shanhua, Tainan City, 74199, Taiwan. E-mail: chiuchongchi@gmail.com; Telephone: +886-76150022-6046; Fax: $+886-7615-0940$

() The author(s). This is an open access article distributed under the terms of the Creative Commons Attribution License (https://creativecommons.org/licenses/by/4.0/). See http://ivyspring.com/terms for full terms and conditions.

Received: 2020.02.09; Accepted: 2020.06.14; Published: 2020.08.25

\begin{abstract}
Objective: The survival of prostate cancer (PC) patients after radiotherapy (RT) has improved over time, but it raises the debate of increased risk of secondary colorectal cancer (SCRC). This study aimed to assess whether RT for PC treatment increases the risk of SCRC in comparison with radical prostatectomy (RP).

Methods: A population-based cohort of PC patients treated only with RT or only with RP between January 2007 and December 2015 was identified from the Taiwan Cancer Registry. The incidence rate of SCRC development was estimated using Cox regression model.

Results: In this study, total 8,797 PC patients treated with either RT $(n=3,219)$ or RP $(n=5,578)$. Patients subjected to RT were elder (higher percentage of $70 \geqq$ years, $p<0.0001$ ) and more advanced clinically (stage III: $22.90 \%$ vs. $11.87 \%$; stage IV: $22.15 \%$ vs. $13.80 \%, p<0.0001$ ), compared to those subjected to RP. More patients subjected to RT had a much higher percentage of autoimmune disease $(22.34 \%$ vs. $18.75 \%, p<0.0001)$ and osteoarthritis and allied disorders $(16.31 \%$ vs. $12.98 \%, p<0.0001$ ). Besides, RT patients had a higher percentage of underlying Crohn's disease $(0.25 \%$ vs. $0.05 \%, p=0.0230)$. Although almost all selected factors were not statistically significant, they presented the positive risk of SCRC for those under RP compared with those among RT. Besides, for PC patients in clinical stage I and II, patients with RP may have borderline significantly protective effects of SCRC compared with those under RT (stage I, HR: 0.14; 95\% C.1.0.01-1.39; $p$ $=0.0929$; stage II, HR: 1.92; 95\% C.I.:0.93-3.95; $p=0.0775$ ). Kaplan-Meier curves for a 3 -year-period, which demonstrated no statistical difference in the risk of SCRC free between PC patients undergoing RT and RP $(p=0.9766)$.
\end{abstract}


Conclusion: Whether or not pelvic RT for PC is associated with an increased risk for SCRC on a population-based level remains a matter of considerable debate. From a clinical perspective, these PC survivors should be counseled accordingly and received continued cancer surveillance with regular colonoscopy follow-up.

Key words: secondary colorectal cancer; prostate cancer; radiotherapy; radical prostatectomy; large population-based study

\section{Introduction}

Prostate cancer (PC) is among the most common cancers in men worldwide. It is estimated at about $1,600,000$ new cases and causes about 366,000 deaths every year [1]. Due to the widespread adoption of the prostate-specific antigen test, the majority of PC are diagnosed at an early stage [2]. Most of those non-metastatic cancers will be treated with radiotherapy (RT) or radical prostatectomy (RP) [3]. However, radiation-induced secondary malignancies are a known but infrequent complication of RT, which would be expected to occur within the irradiated field [4]. In clinical practice, RP and RT have similar oncologic outcomes [5]. However, many controversies still exist regarding related risks after both therapeutic choices, which are associated with different quality-of-life detriments [6-15]. RP predisposes to surgical mortality [16, 17], which may be avoided with RT. Conversely, RT may predispose to secondary malignancies in long-term follow-up [18-25]. Thus, one must consider the side effects of each therapy before informed decisions can be made [26], uniquely identifying whether patients at increased risk of developing a secondary colorectal cancer (SCRC) would help to optimize treatment of the primary PC and to diagnose SCRCs promptly [2].

In the past, only scanty studies tried to investigate the risk of developing an SCRC [27-33]. The literature regarding the risk of RT related SCRC is inconsistent. Some authors have demonstrated an increased risk of rectal cancer [20,34], but others have not $[23,35]$. Similarly, this contradiction also existed in patients of colon cancer $[3,19,20]$. However, many previous studies had short follow-up times and thus included many patients who were not yet at risk of radiation-induced neoplasia [3]. Besides, most studies were originated from Western countries, and it is generally believed that the incidence of PC is lower in Asian countries [36].

Our study focused on comparing the incidence of SCRC after RT and RP for PC. The relative risk of developing an SCRC was analyzed. Besides, we compared the clinical characteristics and oncologic outcomes of PC patients after RP or RT treatment in a nationwide setting.

\section{Materials and Methods}

\section{Study design and data sources}

This study analyzed administrative claims data obtained from the Taiwan Bureau of National Health Insurance (BNHI). Because the BNHI was the sole payer in Taiwan, the BNHI data set covered the information of more than 23 million people, which was assumedly the most comprehensive and reliable data source for the study. Besides, the Taiwan Cancer Registry (TCR) was used to identify cancer patients. TCR established in 1979 to monitor the Taiwan's cancer incidence and the mortality rates. From the 20 items of all newly diagnosed cancers information (short-form database), TCR added detailed diagnosis and treatment items (long-form database) in 2002 for cancer types as oral cavity and pharynx (except nasopharynx), colon and rectum, liver, lung, breast, and cervix. In 2007, the prostate cancer was also added in the long-form database [37, 38].

The subjects of this study were selected from the TCR. The history of the diagnosis claims among those patients obtained from the national health insurance research database (NHIRD). The NHIRD contained a registry of contracted medical facilities, a registry of board-certified physicians, and monthly summaries for all inpatient claims. Since the analysis was limited to aggregate secondary data that could not be used to identify the patients, this study was exempt from full review by the internal review board at this institution. However, the study protocol conformed to the ethical standards established by the Declaration of Helsinki in 1964, which did not require written or verbal consent for data linkage studies.

\section{Study patients}

The TCR included all cases of patients who were derived from the International Classification of Disease codes (ICD-9-CM) and those following a principal diagnosis of malignant neoplasm of the prostate (ICD-9-CM diagnosis code 185) as primary cancer $(\mathrm{n}=36,543)$ from January 2007 to December 2015. It was staged according to the Tumor, Node, Metastasis (TNM) classification. After including either RP (ICD-9-CM procedure code 60.5) or RT (ICD-9-CM procedure code 92.29) as treatment modalities, these samples were eligible patients in this study. However, 
the analysis further excluded patients with no diagnosis of secondary malignant neoplasm of colon or rectum (ICD-9-CM diagnosis codes 153.0, 154.0, $154.1,154.2,154.3,154.8,230.3,230.4,230.5,230.6$ or 197.5), no correct clinical information, or patients receiving neither or both $\mathrm{RT}$ and $\mathrm{RP}$.

It was generally considered that secondary primary cancer required a latency period at least two months after the primary diagnosis to eliminate synchronous primary cancers [39]. RT was not known to cause SCRC in the short term. Thus, we extended the analyses of the incident cases that occurred within 36 months after RP or RT delivery in our study design. Because comorbidities may result in premature mortality and may not allow the development of secondary malignancies, we adjusted for baseline comorbidities, including of Crohn's disease (ICD-9-CM: 569.81), diabetes mellitus (DM)
(ICD-9-CM: 250), end-stage renal disease (ESRD) (ICD-9-CM: 585), hyperlipidemia (ICD-9-CM: 272), liver cirrhosis (LC) (ICD-9-CM: 571.5), chronic obstructive pulmonary disease (COPD) (ICD-9-CM: 490-496), and autoimmune diseases (ICD-9-CM: 274.9, 279.4, 710, 714, 715) which including gout (ICD-9-CM: 274.9), diffuse diseases of connective tissue (ICD-9-CM: 710), osteoarthritis and allied disorders (ICD-9-CM: 715), and rheumatoid arthritis (ICD-9-CM: 714). For avoiding the potential misclassification bias, the cases without correct diagnosis date, RT date, RP date, and information of the clinical stage were excluded. Cases who both received RT or RP during the study period were also excluded. Besides, the cases whose follow-up time fewer than two years were excluded to reduce the effect of a possible competing risk. The flowchart of study subjects' selection presented as Figure 1.

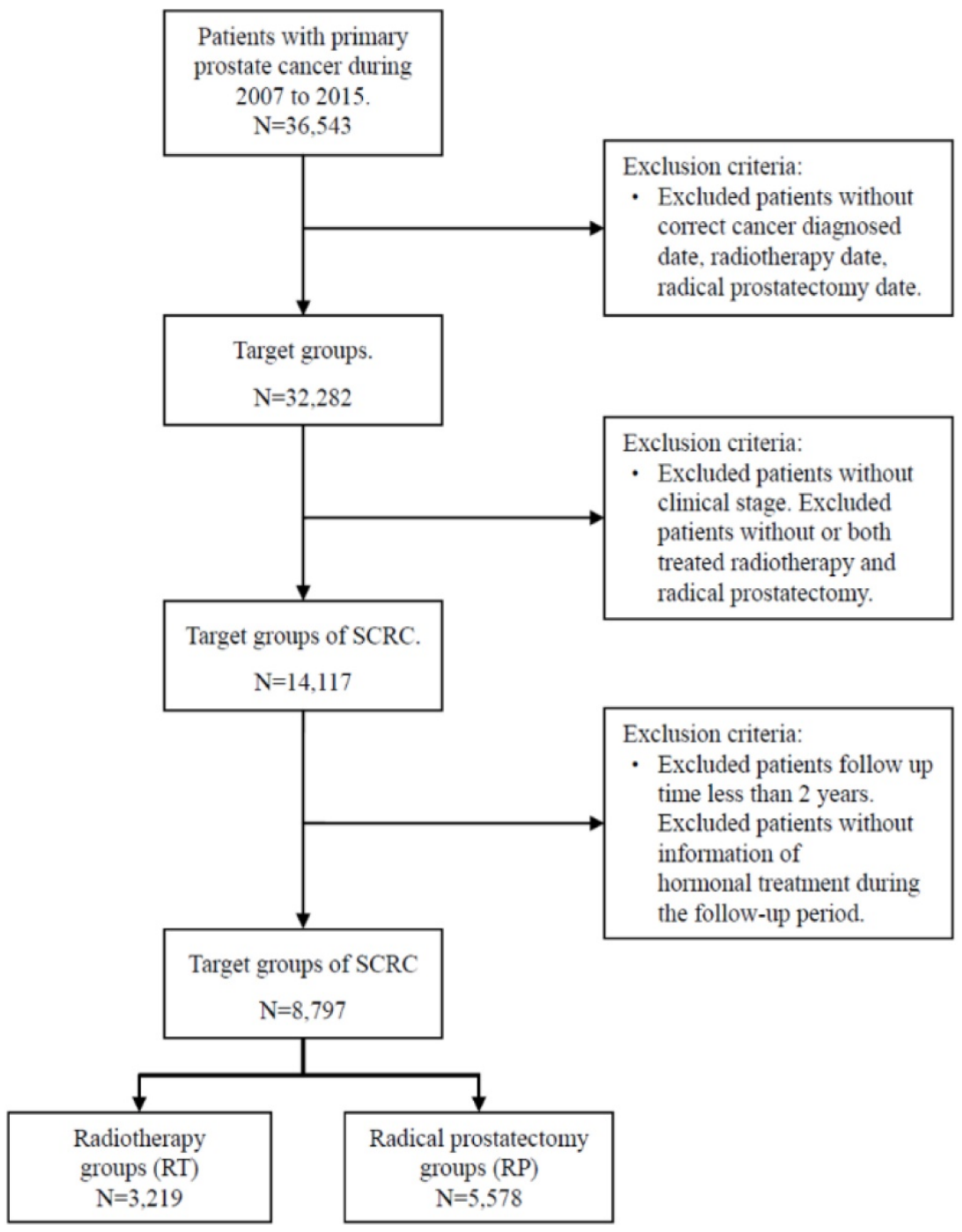

Figure 1. Flowchart for study subject selection 


\section{Statistical Analysis}

Our study population was divided into two subgroups according to the treatment modalities for PC, including RP and RT. For analyses, RP patients were considered controls. Conversely, patients treated with RT during the same period were considered cases.

Pearson's Chi-squared analysis was used to compare the age, clinical stages of $\mathrm{PC}$, and comorbidities between patients with PC treated by RT and those treated by RP. Analyses were stratified by age at PC diagnosis (early-onset $<60$ years, $60-69$ years or late-onset $>70$ years). Age was dichotomized into these groups because these cutoffs have commonly been used in demographic and epidemiologic studies, as well as statistics on the elderly. In addition, Wilcoxon's rank sum test was used to estimate the difference between PC patients treated by RT and those treated by RP for the variables, time to SCRC and time to death.

The trend of SCRC free incidence was calculated using the Kaplan-Meier method. Kaplan-Meier analyses addressed the time to the diagnosis of SCRC after having received either RP or RT. We calculated Kaplan-Meier curves representing the incidence rate of SCRC free development from PC diagnosis. The trend differences between RP and RT groups were compared with the log-rank test. In order to estimate the rare events and control the potential confounders, Cox proportional hazards model with Firth's penalized likelihood approach was constructed to adjust the age at diagnosis, PC clinical stages, hormone therapy, and comorbidities. The stratified analysis of each interested variable was also presented. In addition, we also estimated the other event, rectal cancer, a subtype of colorectal cancer. For all comparisons, a $p$-value of less than 0.05 was considered statistically significant. The statistical software, Statistical Analysis System (SAS) (version 9.4; SAS Institute, Inc, Cary, NC, USA), was used to perform all statistical analyses. Survival curves were generated using STATA version 12 (StataCorp LP, College Station, TX, USA).

\section{Results}

Table 1 showed the descriptive characteristics of 8,797 PC patients treated with either RT $(n=3,219)$ or $\mathrm{RP}(\mathrm{n}=5,578)$ in this study. Patients subjected to RT were elder (higher percentage of $\geq 70$ years, $p<0.0001$ ) and more advanced clinically (stage III: $22.90 \%$ vs. $11.87 \%$; stage IV: $22.15 \%$ vs. $13.80 \%, p<0.0001$ ), compared to those subjected to RP. Besides, more patients subjected to RT had a much higher percentage of autoimmune diseases $(22.34 \%$ vs.
$18.75 \%, p<0.0001)$ and osteoarthritis and allied disorders $(16.31 \%$ vs. $12.98 \%, p<0.0001)$. Besides, RT patients had a higher percentage of underlying Crohn's disease $(0.25 \%$ vs. $0.05 \%, p=0.0230)$, despite the patient number was scarce (8 vs. 3 ).

Table 1. Characteristics of prostate cancer (PC) patients

\begin{tabular}{|c|c|c|c|}
\hline Variable & $\begin{array}{l}\text { Prostate cancer } \\
\text { with RP }(N=5578)\end{array}$ & $\begin{array}{l}\text { Prostate cancer } \\
\text { with RT }(\mathrm{N}=3219)\end{array}$ & P-value \\
\hline \multicolumn{4}{|l|}{ Age at diagnosed, years, $\mathrm{n}(\%)$} \\
\hline$<60$ & 695(12.46) & $190(5.90)$ & $<.0001$ \\
\hline $60-69$ & 1999(35.84) & $763(23.70)$ & \\
\hline$\geq 70$ & $2884(51.70)$ & $2266(70.39)$ & \\
\hline \multicolumn{4}{|l|}{ Clinical stage, $\mathrm{n}(\%)$} \\
\hline I & $889(15.94)$ & $130(4.04)$ & $<.0001$ \\
\hline II & $3257(58.39)$ & $1639(50.92)$ & \\
\hline III & $662(11.87)$ & $737(22.90)$ & \\
\hline IV & $770(13.80)$ & $713(22.15)$ & \\
\hline \multicolumn{4}{|l|}{ Comorbidity, $\mathrm{n}(\%)$} \\
\hline Crohn's disease & $3(0.05)$ & $8(0.25)$ & 0.0230 \\
\hline $\mathrm{DM}$ & $1139(20.42)$ & $655(20.35)$ & 0.9360 \\
\hline ESRD & $164(2.94)$ & $116(3.60)$ & 0.0877 \\
\hline Hyperlipidemia & $1200(21.51)$ & $683(21.22)$ & 0.7450 \\
\hline Autoimmune & 1046(18.75) & $719(22.34)$ & $<.0001$ \\
\hline Gout & $332(5.95)$ & $202(6.28)$ & 0.5408 \\
\hline $\begin{array}{l}\text { Diffuse diseases of connective } \\
\text { tissue }\end{array}$ & $26(0.47)$ & $14(0.43)$ & 0.8341 \\
\hline Rheumatoid arthritis & $31(0.56)$ & $20(0.62)$ & 0.6965 \\
\hline $\begin{array}{l}\text { Osteoarthrosis and allied } \\
\text { disorders }\end{array}$ & $724(12.98)$ & $525(16.31)$ & $<.0001$ \\
\hline LC & $296(5.31)$ & $183(5.68)$ & 0.4512 \\
\hline COPD & $633(11.35)$ & $409(12.71)$ & 0.0577 \\
\hline $\mathrm{SCRC}, \mathrm{n}(\%)$ & $53(0.95)$ & $32(0.99)$ & 0.8392 \\
\hline Colon & $44(0.84)$ & $25(0.78)$ & 0.5760 \\
\hline Rectum & $9(0.16)$ & $7(0.22)$ & 0.5519 \\
\hline $\begin{array}{l}\text { Time to SCRC after survived } 2 \\
\text { years, median (Q1-Q3) }\end{array}$ & $1.39(0.36-2.25)$ & $0.91(0.40-1.90)$ & 0.4661 \\
\hline Mortality, n(\%) & 996(17.86) & $722(22.43)$ & $<.0001$ \\
\hline $\begin{array}{l}\text { Time to death, after survived } 2 \\
\text { years, median(Q1-Q3) }\end{array}$ & $1.55(0.69-2.91)$ & $1.72(0.80-3.00)$ & 0.0627 \\
\hline $\begin{array}{l}\text { Subjects with hormone therapy, } \\
\mathrm{n}(\%)\end{array}$ & $2270(40.70)$ & $2463(76.51)$ & $<.0001$ \\
\hline Radiation colitis after PC, $\mathrm{n}(\%)$ & & $122(3.79)$ & \\
\hline
\end{tabular}

Table 2 showed the results of the adjusted hazard ratio of SCRC after therapy by a different stratum of selected confounding factors. Although almost all selected factors were not statistically significant, they presented the definite risk of SCRC for those under RP compared with those among RT. Besides, for PC patients in clinical stage I and II, patients with RP may have borderline significantly protective effects of SCRC compared with those under RT (stage I, HR: 0.14; 95\% C.I.:0.01-1.39; $p=0.0929$; stage II, HR: 1.92; 95\% C.I.:0.93-3.95; $p=0.0775$ ). Similarly, no significant statistical difference was noted while only rectal cancer patient group was analyzed individually from all our SCRC patients.

Figure 2 displayed the Kaplan-Meier curves for a 3-year-period, which demonstrated no statistical difference in the incidence rate of SCRC free between PC patients undergoing RT and RP $(p=0.9766)$. 


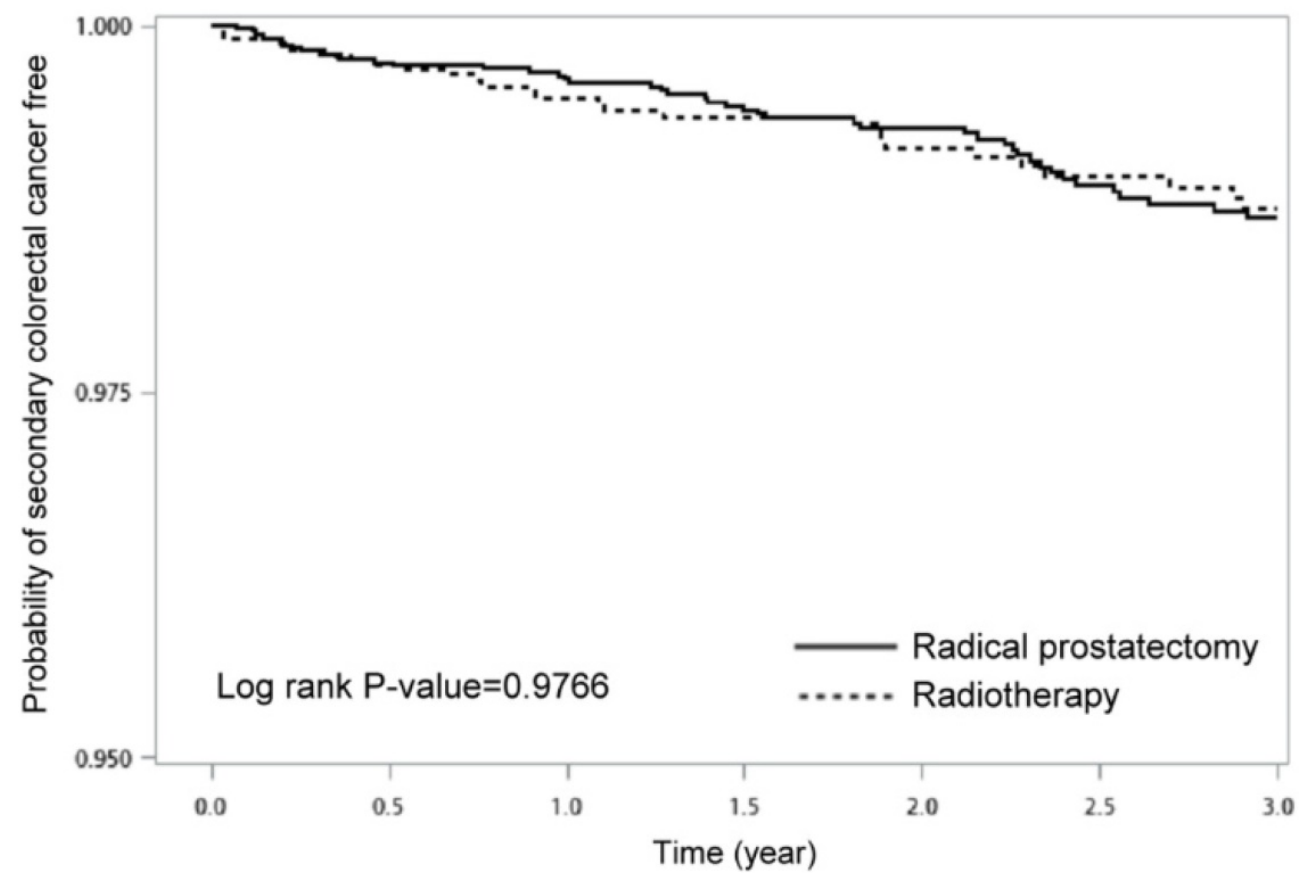

Figure 2. Probability of SCRC free between prostate cancer patients with radical prostatectomy and those with radiotherapy

Table 2. Adjusted hazard ratio of SCRC and rectal after therapy by different stratum

\begin{tabular}{|c|c|c|c|c|}
\hline RP vs RT & $\begin{array}{l}\text { Risk of SCRC } \\
\text { HR }(95 \% \text { CI })^{*}\end{array}$ & P-value & $\begin{array}{l}\text { Risk of rectal cancer } \\
\text { HR }(95 \% \mathrm{CI})^{*}\end{array}$ & P-value \\
\hline All subjects & $1.47(0.87-2.49)$ & 0.1468 & $1.44(0.47-4.42)$ & 0.5209 \\
\hline \multicolumn{5}{|c|}{$\begin{array}{l}\text { Age at diagnosed, } \\
\text { years }\end{array}$} \\
\hline$<60$ & $0.83(0.02-38.88)$ & 0.9221 & - & \\
\hline $60-69$ & $1.07(0.21-5.41)$ & 0.9368 & $0.43(0.03-6.90)$ & 0.5518 \\
\hline $70 \geqq$ & $1.44(0.82-2.53)$ & 0.2074 & $1.74(0.51-5.96)$ & 0.3785 \\
\hline \multicolumn{5}{|c|}{ Clinical stage } \\
\hline I & $0.14(0.01-1.39)$ & 0.0929 & $0.34(<.01-71.68)$ & 0.6951 \\
\hline II & $1.92(0.93-3.95)$ & 0.0775 & $1.52(0.35-6.55)$ & 0.5717 \\
\hline III & $1.84(0.47-7.22)$ & 0.3805 & $0.76(0.08-7.11)$ & 0.8122 \\
\hline IV & $0.64(0.19-2.08)$ & 0.4535 & - & \\
\hline \multicolumn{5}{|l|}{ Comorbidity } \\
\hline \multicolumn{5}{|l|}{$\mathrm{DM}$} \\
\hline Yes & $1.29(0.33-5.10)$ & 0.7158 & $0.19(<.01-40.18)$ & 0.5419 \\
\hline No & $1.51(0.85-2.67)$ & 0.1607 & $1.80(0.56-5.85)$ & 0.3259 \\
\hline \multicolumn{5}{|l|}{ ESRD } \\
\hline Yes & $0.71(<.01-230.51)$ & 0.9060 & $0.71(<.01-230.51)$ & 0.9060 \\
\hline No & $1.43(0.85-2.42)$ & 0.1822 & $1.28(0.41-4.02)$ & 0.6744 \\
\hline \multicolumn{5}{|c|}{ Hyperlipidemia } \\
\hline Yes & $1.32(0.25-6.89)$ & 0.7427 & $0.43(<.01-80.22)$ & 0.7505 \\
\hline No & $1.49(0.85-2.59)$ & 0.1624 & $1.65(0.51-5.37)$ & 0.4039 \\
\hline \multicolumn{5}{|c|}{ Autoimmune } \\
\hline Yes & $2.98(1.00-8.88)$ & 0.0500 & $1.59(0.08-31.48)$ & 0.7609 \\
\hline No & $1.15(0.63-2.11)$ & 0.6445 & $1.32(0.39-4.53)$ & 0.6561 \\
\hline \multicolumn{5}{|l|}{ LC } \\
\hline Yes & 5.84(0.38-90.17) & 0.2064 & $1.64(0.01-510.44)$ & 0.8652 \\
\hline No & $1.34(0.78-2.29)$ & 0.2919 & $1.28(0.41-4.00)$ & 0.6778 \\
\hline \multicolumn{5}{|l|}{ COPD } \\
\hline Yes & $9.54(0.27-334.38)$ & 0.2140 & $2.89(0.02-545.35)$ & 0.6920 \\
\hline No & $1.31(0.77-2.24)$ & 0.3264 & $1.26(0.40-4.03)$ & 0.6943 \\
\hline \multicolumn{5}{|c|}{ Hormone therapy } \\
\hline Yes & $1.28(0.69-2.39)$ & 0.4339 & $1.55(0.44-5.47)$ & 0.4993 \\
\hline No & $1.59(0.54-4.68)$ & 0.3972 & $0.62(0.06-6.63)$ & 0.6930 \\
\hline
\end{tabular}

*The HR was adjusted by age, clinical stage, and the listed comorbidities.

\section{Discussion}

In the United States, $11 \%$ of men are diagnosed with PC over their lifetime, with the incidence generally rising with age; there are an estimated 165,000 cases and 29,000 deaths annually [40].

Several different treatment strategies could be considered for patients with PC, including active surveillance, $\mathrm{RP}$, and radiation therapy ( $\mathrm{RT}$ and/or brachytherapy). Strategy selection by physicians mainly depends on cancer risk assessment and possible residual lifespan as well as patient preferences [39]. RP for invasive PC is associated with positive margin rates in $10 \%$ to $50 \%$ of resected specimens. Post-operative RT may benefit patients who have an organ-confined PC with positive margins [41]. RT provides the patients with advanced cancer an effective treatment, and it is expected to inhibit the potential of cancer cell multiplication and lead to cell death [42]. However, the long-life expectancy of these PC patients exposes them to the possibility of developing SCRC [39], which would be considered one of the most worrisome adverse effects of RT [26].

Among cancer of different organs, patients with PC provide an excellent opportunity to study the late effects of RT, because sufficiently large numbers of patients are available for study, the life expectancy of these men well exceeds 25 years [43], non-irradiated patients can be compared, and radiation doses to organs other than the prostate can be estimated accurately in prospective studies. 
Factors associated with the development of rectal toxicity after RT for PC are variable and may be categorized as they relate to radiation delivery or patient characteristics [44]. Although the correlation between radiation dose and rectal toxicity is somewhat intuitive and well accepted, the effect of radioresistance and repopulation at the primary site and/or at the malignant areas cause a paramount challenge in cancer control [42].

Secondary cancers were primarily defined as having different histologic features from primary cancer according to a criterion by Warren and Gated to distinguish recurrence or metastasis from the primary [45]. Besides the possible effect of RT, factors contributing to the development of primary cancer probably also play a specific key in secondary cancer development [46]. Establishing an association between malignancies may shed light on possible shared carcinogenic mechanisms, reveal an impact of treatment for one on the development of the other, and help develop evidence-based surveillance protocols [22]. Some studies mentioned that cancer survivors are at increased risk of developing second cancer compared with an age- and the sex-matched general population [47]. This increased risk is multifactorial and has been explained by several factors, such as lifestyle factors, genetic susceptibility, and administered chemotherapy or RT. For example, men with PC had a higher risk of developing bladder, kidney, soft tissue, and endocrine cancers. However, some studies showed converse results. Some researchers observed that PC survivors had an overall $40 \%$ lower risk of secondary primary cancer development in comparison with the general male in the US. They were noted with a lower occurrence risk of lung, bronchus, larynx, leukemia, neoplasms of the pharynx, oral cavity, esophagus, stomach, colon, rectum, liver, gall bladder, and pancreas, [48-52]. For patients of PC, it is not entirely clear about the phenomenon of risk reduction, but we think that the old age at the time of diagnosis of PC may be one of the reasons [39]. The mean age of PC diagnosis is about 67 years [53]; the elder who has PC might not have the same chance of a second diagnosis as all US men [39]. This might be an artifact of case-finding because advanced age at initial diagnosis of PC is associated with an underascertainment of second cancers [54]. However, enhanced surveillance and screening after a PC diagnosis may have early detection of certain cancers, which causes a false phenomenon of the increased risk [39].

$\mathrm{RT}$ is used as a definitive treatment strategy in approximately $25 \%$ of localized PC patients [55]. In general, exposure to ionizing radiation is considered to be a potential cause of cancer [2]. Previous studies using one same SEER database have produced conflicting results concerning the risk of rectal cancer after RT for PC. Bexter et al. found a 1.7-fold increased risk of developing subsequent rectal cancer in patients treated with RT for PC compared to those treated with RP [3], while Kendal et al. could not demonstrate a similar outcome [56]. Huo et al. expanded the SEER data until 2005 and demonstrated that there was indeed an increased risk for rectal cancer, but only after $>10$ years of follow-up [57]. Likewise, some studies reported an increased risk for rectal cancer after prostate irradiation $[2,25,26,39]$, whereas others found no association [22, 58-60]. Possible reasons for this discrepancy are a limited sample size or short follow-up, differences in lag periods, and variation in statistical methods [61].

In principle, radiation-induced second cancers are defined as those cancers occurring inside or close to radiation-exposed regions (field congruence) [62]. Generally, secondary cancers are predominantly expected to occur in the rectum and rectosigmoid colon than other parts of the colon. For evaluation of the radiation effect on the risk of developing secondary colorectal cancer, Baxter et al. compared the related data of three different sites: rectum, rectosigmoid/sigmoid/cecum, and the rest of the colon according to the risk of radiation exposure. They noted a significantly increased risk of rectal cancer among men who received RT, with a hazard ratio of 1.7 (95\% CI, 1.4-2.2), in comparison to the male who did not, but there was no increased risk of cancer in the rest of the colon [3]. However, Hegemann et al. showed that there was a $70 \%$ higher risk of rectal cancer in patients with RT compared to those treated with RP only and a less increased risk of colon cancer [4]. Moon et al. even found that patients treated with RT had significantly higher odds of developing both rectum and sigmoid colon cancer (OR 5 1.60; and OR 5 1.26, respectively; $p<0.05$ ) [19]. However, all these results of SCRC were different from the conclusion of Mc Master et al. after re-evaluation of the SEER database, which showed no increased risk for either colon or rectum cancer. However, we had the same conclusion as that of Mc Master et al. Besides the possible causes mentioned above, the differences in the results among these studies may also be related to differences in the study design and analysis, outcome of interest, comparison population, measure of risk, etc. [59]

Radiation-induced second cancers manifest with a frequency that could be obscured by the background incidence of spontaneous second cancers. This frequency seems so low as to make prospective randomized comparisons very difficult, and the potential for unrecognized confounders is such that 
the retrospective analysis of large population databases can be complicated [63]. Thus, the effects of therapeutic radiation and the potential for radiation-induced second cancer should be considered in the context of the background of spontaneously occurring cancer, particularly in older populations. However, there is no specific marker available to allow a precise distinction between radiation-induced second cancers and non-radiation induced second cancer; all assessments are based on epidemiological and/or statistical analysis [4]. Based on these reasons, many experts have suggested men undergoing radiation for $\mathrm{PC}$ should undergo regular endoscopic evaluation $[3,26]$.

Latency periods represent the time from radiation exposure until the diagnosis of subsequent cancer and latency period thresholds have been introduced to second cancer analyses to reduce possible bias from synchronous tumors. Unfortunately, there is no consensus regarding the length of time, after which malignancies are considered secondary to RT $[4,25]$. Between studies, the latency period thresholds in the reviewed studies vary from 1 month up to 15 years, often without evidence supporting the time thresholds $[16,17,39$, $58,64,65]$. This may have led to a discrepancy in the outcomes [25]. Nonetheless, it is debatable whether the length of latency periods is the same, disregarding the patient's age or specific organs at risk [66, 67]. Therefore, a fixed latency period is often introduced to reduce the chances of such bias [61]. Some studies reported on multiple fixed latency periods and could, therefore, be entered into the meta-analysis repetitively. There was a significant increase of rectal cancers in time since primary treatment with calculated relative risks (RRs) for developing rectal cancer of 1.31 (95\% CI 1.104-1.66), 1.51 (95\% CI 0.972.33), 1.95 (95\% CI 1.51-2.53), and 2.49 (95\% CI 1.48$4.19)$, for $0-2$ months, up to 5 years, up to 10 years and up to 20 years respectively ( $p=0.0006$ ) [61]. Until this consensus regarding the latency period is clarified, it will remain debatable whether the subsequent rate of malignancies can be interpreted as clinically meaningful [25]. In this study, we applied a shorter interval (3 years) to exclude the possibility of "synchronous" colorectal cancer. First, because the pathways leading to colorectal carcinogenesis in this unique setting remained unknown, any cutoff was arbitrary, and cancer occurring after three years was probably as much a secondary malignancy as a one occurring after five years. Secondly, from a patient perspective, any increase in morbidity after a specific treatment was essential to acknowledge whether genuinely secondary to the applied therapy or not.
In Table 2 of our study, we noted a definite risk of SCRC for the patients under RP compared with those among RT, especially cases in clinical stage I (HR: 0.14; 95\% C.I.:0.01-1.39; $p=0.0929$ ). This phenomenon of borderline significantly protective effects of SCRC on patients with RP is hard to clarify. However, we think it may be related to the longer life expectancy of stage I PC patients than those of other stages, and no exposure to the radiation injury before. Thus they could obviate the risk of radiation toxicity effect on SCRC occurrence in a longer follow-up.

Our study represented a significant improvement over many prior institutional analyses of the SCRC after RT for PC. First, our study was based on a large, population-based design, and our results benefited from well-defined data collection and excellent quality standards designed to ensure that all eligible cases were selected, which allowed our results to be generalized across the Asian countries. Second, our population benefited from universal national health insurance. Therefore, diagnostic rates may differ from those populations in which economic and health care considerations may prevent the same rate of use and access to health resources, as was the case in the Western countries. Third, the uniqueness of our findings related to their origin. Most of our patients originated from a genetically, environmentally, and health economically similar population, compared with virtually all previous studies.

However, the current study was, in part, limited by the fact that the RT group included patients treated with all forms of radiation therapies, including conventional external beam RT, 3-dimensional conformal therapy, intensity-modulated radiation therapy, brachytherapy, and combination radiation therapy. Thus, the risk of subsequent colorectal cancer associated with these particular forms of radiation therapies could not be investigated explicitly by our retrospective studies, despite the fact that most patients had received conventional external beam RT during our study period. Second, data on the dosage or field of radiation are unavailable, and we were not aware of the doses of radiation administered to patients who received RT and, therefore, a dose-risk relationship of RT with SCRC could not be assessed. Third, we did not control for colorectal cancer risk factors such as a change in lifestyle after prostate cancer therapy, smoking habits, or family history. Fourth, we did not examine other adverse effects of RT and RP.

\section{Conclusion}

Our study did not show differences in SCRC incidence between patients with PC treated with RP 
or RT after hazard adjustment by different stratum. However, this study should not be interpreted to discount the occurrence of radiation-induced tumors or provide data to change the guidelines for surveillance for colorectal cancer in previously irradiated patients.

\section{Acknowledgements}

This research was supported by Health and Welfare surcharge on tobacco products (MOHW109-TDU-B-212-134020, Wan Fang Hospital, Chi Mei Medical Center, and Hualien Tzu-Chi Hospital Joing Cancer Center Grant-Focus on Colon Cancer Research). We are also grateful to Health Data Science Center, National Cheng Kung University Hospital for providing administrative and technical support.

\section{Author Contributions}

Chung-Han Ho analyzed the statistical data, made the tables and graph, applied for the fund; Kuo-Chen Cheng provided opinion and feedback; Chien-Ming Chao provided opinion; Chih-Cheng Lai provided opinion; Shyh-Ren Chiang provided opinion; Chin-Ming Chen provided opinion; Kuang-Ming Liao provided opinion; Jhi-Joung Wang provided opinion; Po-Huang Lee provided opinion; Chao-Ming Hung provided opinion; Chi-Ming Tai provided opinion; Chong-Chi Chiu designed the study, collected data records, assisted the statistical data analysis, obtained IRB approval, wrote the first and final draft, and supervision of the study.

\section{Institutional review board statement}

The study was reviewed and approved by the Chi Mei Medical Center Institutional Review Board.

\section{Competing Interests}

The authors have declared that no competing interest exists.

\section{References}

1. Global Burden of Disease Cancer Collaboration, Fitzmaurice $C$, Allen C, Barber RM, Barregard L, Bhutta ZA, et al. Global, Regional, and National Cancer Incidence, Mortality, Years of Life Lost, Years Lived With Disability, and Disability-Adjusted Life-years for 32 Cancer Groups, 1990 to 2015: A Systematic Analysis for the Global Burden of Disease Study. JAMA Oncol. 2017; 3: 524-48.

2. Joung JY, Lim J, Oh CM, Jung KW, Cho H, Kim SH, et al. Risk of Second Primary Cancer among Prostate Cancer Patients in Korea: A Population-Based Cohort Study. PLoS One. 2015; 10: e0140693.

3. Baxter NN, Tepper JE, Durham SB, Rothenberger DA, Virnig BA. Increased risk of rectal cancer after prostate radiation: a population-based study. Gastroenterology. 2005; 128: 819-24

4. Hegemann NS, Schlesinger-Raab A, Ganswindt U, Hörl C, Combs SE, Hölzel D, Gschwend JE, et al. Risk of second cancer following radiotherapy for prostate cancer: a population-based analysis. Radiat Oncol. 2017; 12: 2.

5. Kupelian PA, Elshaikh M, Reddy CA, Zippe C, Klein EA. Comparison of the efficacy of local therapies for localized prostate cancer in the prostate-specific antigen era: a large single-institution experience with radical prostatectomy and external-beam radiotherapy. J Clin Oncol. 2002: 20:3376-85.
6. Litwin MS, McGuigan KA, Shpall AI, Dhanani N. Recovery of health related quality of life in the year after radical prostatectomy: early experience. J Urol. 1999; 161: 515-9.

7. Litwin MS, Hays RD, Fink A, Ganz PA, Leake B, Leach GE, et al. Quality-of-life outcomes in men treated for localized prostate cancer. JAMA. 1995; 273: 129-35.

8. Karakiewicz PI, Bhojani N, Neugut A, Shariat SF, Jeldres C, Graefen M, et al. The effect of comorbidity and socioeconomic status on sexual and urinary function and on general health-related quality of life in men treated with radical prostatectomy for localized prostate cancer. J Sex Med. 2008; 5: 919-27.

9. Hanlon AL, Watkins Bruner D, Peter R, Hanks GE. Quality of life study in prostate cancer patients treated with three-dimensional conformal radiation therapy: comparing late bowel and bladder quality of life symptoms to that of the normal population. Int J Radiat Oncol Biol Phys. 2001; 49: 51-9.

10. Lilleby W, Fosså SD, Waehre HR, Olsen DR. Long-term morbidity and quality of life in patients with localized prostate cancer undergoing definitive radiotherapy or radical prostatectomy. Int J Radiat Oncol Biol Phys. 1999; 43: 735-43.

11. Leborgne F, Fowler J. Acute toxicity after hypofractionated conformal radiotherapy for localized prostate cancer: nonrandomized contemporary comparison with standard fractionation. Int J Radiat Oncol Biol Phys. 2008; 72: 770-6.

12. Fonteyne V, Villeirs G, Speleers B, De Neve W, De Wagter C, Lumen N, et al. Intensity-modulated radiotherapy as primary therapy for prostate cancer: report on acute toxicity after dose escalation with simultaneous integrated boost to intraprostatic lesion. Int J Radiat Oncol Biol Phys. 2008; 72: 799-807.

13. Faria SL, Souhami L, Joshua B, Vuong T, Freeman CR. Reporting late rectal toxicity in prostate cancer patients treated with curative radiation treatment. Int J Radiat Oncol Biol Phys. 2008; 72: 777-81.

14. Ferrer M, Suárez JF, Guedea F, Fernández P, Macías V, Mariño A, et al. Health-related quality of life 2 years after treatment with radical prostatectomy, prostate brachytherapy, or external beam radiotherapy in patients with clinically localized prostate cancer. Int J Radiat Oncol Biol Phys. 2008; $72:$ 421-32

15. Mols F, Korfage IJ, Vingerhoets AJ, Kil PJ, Coebergh JW, Essink-Bot ML, et al. Bowel, urinary, and sexual problems among long-term prostate cancer survivors: a population-based study. Int J Radiat Oncol Biol Phys. 2009; 73: 30-8.

16. Kry SF, Followill D, White RA, Stovall M, Kuban DA, Salehpour M. Uncertainty of calculated risk estimates for secondary malignancies after radiotherapy. Int J Radiat Oncol Biol Phys. 2007; 68: 1265-71.

17. Damber JE, Aus G. Prostate cancer. Lancet. 2008; 371:1710-21.

18. Bostrom PJ, Soloway MS. Secondary cancer after radiotherapy for prostate cancer: should we be more aware of the risk? Eur Urol. 2007; 52: 973-82.

19. Moon K, Stukenborg GJ, Keim J, Theodorescu D. Cancer incidence after localized therapy for prostate cancer. Cancer. 2006; 107: 991-8.

20. Brenner DJ, Curtis RE, Hall EJ, Ron E. Second malignancies in prostate carcinoma patients after radiotherapy compared with surgery. Cancer. 2000; 88: 398-406.

21. Liauw SL, Sylvester JE, Morris CG, Blasko JC, Grimm PD. Second malignancies after prostate brachytherapy: incidence of bladder and colorectal cancers in patients with 15 years of potential follow-up. Int J Radiat Oncol Biol Phys. 2006; 66: 669-73.

22. Boorjian S, Cowan JE, Konety BR, DuChane J, Tewari A, Carroll PR, et al. Bladder cancer incidence and risk factors in men with prostate cancer: results from Cancer of the Prostate Strategic Urologic Research Endeavor. J Urol. 2007; 177 : 883-7.

23. Neugut AI, Ahsan H, Robinson E, Ennis RD. Bladder carcinoma and other second malignancies after radiotherapy for prostate carcinoma. Cancer. 1997; 79: $1600-4$

24. Kry SF, Salehpour M, Followill DS, Stovall M, Kuban DA, White RA, et al. The calculated risk of fatal secondary malignancies from intensity-modulated radiation therapy. Int J Radiat Oncol Biol Phys. 2005; 62: 1195-203.

25. Bhojani N, Capitanio U, Suardi N, Jeldres C, Isbarn H, Shariat SF, et al. The rate of secondary malignancies after radical prostatectomy versus external beam radiation therapy for localized prostate cancer: a population-based study on 17,845 patients. Int J Radiat Oncol Biol Phys. 2010; 76: 342-8.

26. Margel D, Baniel J, Wasserberg N, Bar-Chana M, Yossepowitch O. Radiation therapy for prostate cancer increases the risk of subsequent rectal cancer. Ann Surg. 2011; 254: 947-50

27. Huang J, Kestin LL, Ye H, Wallace M, Martinez AA, Vicini FA. Analysis of second malignancies after modern radiotherapy versus prostatectomy for localized prostate cancer. Radiother Oncol. 2011; 98: 81-6.

28. Gillessen S, Templeton A, Marra G, Kuo YF, Valtorta E, Shahinian VB. Risk of colorectal cancer in men on long-term androgen deprivation therapy for prostate cancer. I Natl Cancer Inst. 2010: 102: 1760-70.

29. Templeton A, Marra G, Valtorta E, Heinimann K, Müller H, Köberle D, et al. Concordant colon tumors in monozygotic twins previously treated for prostate cancer. Fam Cancer. 2009; 8: 167-71.

30. Müller AC, Ganswindt U, Bamberg M, Belka C. Risk of second malignancies after prostate irradiation? Strahlenther Onkol. 2007; 183: 605-9.

31. Kellen E, Zeegers MP, Dirx M, Houterman S, Droste J, Lawrence G, et al. Occurrence of both bladder and prostate cancer in five cancer registries in Belgium, The Netherlands and the United Kingdom. Eur J Cancer. 2007; 43: 1694-700. 
32. Johnstone PA, Powell CR, Riffenburgh R, Rohde DC, Kane CJ. Second primary malignancies in T1-3N0 prostate cancer patients treated with radiation therapy with 10-year followup. J Urol. 1998; 159: 946-9.

33. Greenberg RS, Rustin ED, Clark WS. Risk of genitourinary malignancies after cancer of the prostate. Cancer. 1988; 61: 396-401.

34. Pickles $\mathrm{T}$, Phillips $\mathrm{N}$. The risk of second malignancy in men with prostate cancer treated with or without radiation in British Columbia, 1984-2000. Radiother Oncol. 2002; 65: 145-51.

35. Movsas B, Hanlon AL, Pinover W, Hanks GE. Is there an increased risk of second primaries following prostate irradiation? Int J Radiat Oncol Biol Phys. 1998; 41: 251-5.

36. Hsing AW, Devesa SS. Trends and patterns of prostate cancer: what do they suggest? Epidemiol Rev. 2001; 23: 3-13.

37. Chiang CJ, You SL, Chen CJ, Yang YW, Lo WC, Lai MS. Quality assessment and improvement of nationwide cancer registration system in Taiwan: a review. Jpn J Clin Oncol. 2015; 45: 291-6.

38. Chiang CJ, Wang YW, Lee WC. Taiwan's Nationwide Cancer Registry System of 40 years: Past, present, and future. J Formos Med Assoc. 2019; 118: 856-8.

39. Davis EJ, Beebe-Dimmer JL, Yee CL, Cooney KA. Risk of second primary tumors in men diagnosed with prostate cancer: a population-based cohort study. Cancer. 2014; 120: 2735-41.

40. Siegel RL, Miller KD, Jemal A. Cancer statistics, 2018. CA Cancer J Clin. 2018; 68: 7-30.

41. Dillman RO, Hafer R, Cox $\mathrm{C}$, McClure SE. Overall survival benefit from postoperative radiation therapy for organ-confined, margin-positive prostate cancer. Int J Radiat Oncol Biol Phys. 2011; 79: 719-23.

42. Baskar R, Dai J, Wenlong N, Yeo R, Yeoh KW. Biological response of cancer cells to radiation treatment. Front Mol Biosci. 2014; 1: 24.

43. Critz FA, Benton JB, Shrake P, Merlin ML. 25-Year disease-free survival rate after irradiation for prostate cancer calculated with the prostate specific antigen definition of recurrence used for radical prostatectomy. J Urol. 2013; 189: 878-83.

44. Garg AK, Mai WY, McGary JE, Grant WH 3rd, Butler EB, Teh BS. Radiation proctopathy in the treatment of prostate cancer. Int J Radiat Oncol Biol Phys. 2006; 66: 1294-305.

45. Kapp DS, Fischer D, Grady KJ, Schwartz PE. Subsequent malignancies associated with carcinoma of the uterine cervix: including an analysis of the effect of patient and treatment parameters on incidence and sites of metachronous malignancies. Int J Radiat Oncol Biol Phys. 1982; 8: 197-205.

46. Rombouts AJM, Hugen N, Elferink MAG, Feuth T, Poortmans PMP, Nagtegaal ID, et al. Incidence of second tumors after treatment with or without radiation for rectal cancer. Ann Oncol. 2017; 28: 535-40.

47. Liu L, de Vries E, Louwman M, Aben K, Janssen-Heijnen M, Brink M, et al. Prevalence of multiple malignancies in the Netherlands in 2007. Int J Cancer. 2011; 128: 1659-67.

48. Kleinerman RA, Liebermann JV, Li FP. Second cancer following cancer of the male genital system in Connecticut, 1935-82. Natl Cancer Inst Monogr. 1985; 68: $139-47$.

49. Osterlind A, Rørth M, Prener A. Second cancer following cancer of the male genital system in Denmark, 1943-80. Natl Cancer Inst Monogr. 1985; 68: 341-7.

50. Teppo L, Pukkala E, Saxén E. Multiple cancer--an epidemiologic exercise in Finland. J Natl Cancer Inst. 1985; 75: 207-17.

51. Liskow AS, Neugut AI, Benson M, Olsson CA, Birkhoff J, Chang CH. Multiple primary neoplasms in association with prostate cancer in black and white patients. Cancer. 1987; 59: 380-4.

52. McCredie M, Macfarlane GJ, Stewart J, Coates M. Second primary cancers following cancers of the kidney and prostate in New South Wales (Australia), 1972-91. Cancer Causes Control. 1996; 7: 337-44.

53. Siegel R, Naishadham D, Jemal A. Cancer statistics, 2012. CA Cancer J Clin. 2012; 62: 10-29.

54. Curtis RE, Boice JD Jr, Kleinerman RA, Flannery JT, Fraumeni JF Jr. Summary: multiple primary cancers in Connecticut, 1935-82. Natl Cancer Inst Monogr. 1985; 68: 219-42.

55. Cooperberg MR, Broering JM, Carroll PR. Time trends and local variation in primary treatment of localized prostate cancer. J Clin Oncol. 2010; 28: 1117-23.

56. Kendal WS, Eapen L, Macrae R, Malone S, Nicholas G. Prostatic irradiation is not associated with any measurable increase in the risk of subsequent rectal cancer. Int J Radiat Oncol Biol Phys. 2006; 65: 661-8.

57. Huo D, Hetzel JT, Roy H, Rubin DT. Association of colorectal cancer and prostate cancer and impact of radiation therapy. Cancer Epidemiol Biomarkers Prev. 2009; 18: 1979-85.

58. Hinnen KA, Schaapveld M, van Vulpen M, Battermann JJ, van der Poel H, van Oort IM, et al. Prostate brachytherapy and second primary cancer risk: a competitive risk analysis. J Clin Oncol. 2011; 29: 4510-5.

59. Rapiti E, Fioretta G, Verkooijen HM, Zanetti R, Schmidlin F, Shubert H, et al. Increased risk of colon cancer after external radiation therapy for prostate cancer. Int J Cancer. 2008; 123: 1141-5.

60. Hamilton SN, Tyldesley S, Hamm J, Jiang WN, Keyes M, Pickles T, et al. Incidence of second malignancies in prostate cancer patients treated with low-dose-rate brachytherapy and radical prostatectomy. Int J Radiat Oncol Biol Phys. 2014; 90: 934-41.

61. Rombouts AJM, Hugen N, van Beek JJP, Poortmans PMP, de Wilt JHW, Nagtegaal ID. Does pelvic radiation increase rectal cancer incidence? - A systematic review and meta-analysis. Cancer Treat Rev. 2018; 68: 136-44.
62. Zhang $R$, Mirkovic $D$, Newhauser WD. Visualization of risk of radiogenic second cancer in the organs and tissues of the human body. Radiat Oncol. 2015; 10: 107.

63. Kendal WS, Nicholas G. A population-based analysis of second primary cancers after irradiation for rectal cancer. Am J Clin Oncol. 2007; 30: 333-9.

64. Xu XG, Bednarz B, Paganetti H. A review of dosimetry studies on external-beam radiation treatment with respect to second cancer induction. Phys Med Biol. 2008; 553: R193-241.

65. Suit H, Goldberg S, Niemierko A, Ancukiewicz M, Hall E, Goitein M, et al. Secondary carcinogenesis in patients treated with radiation: a review of data on radiation-induced cancers in human, non-human primate, canine and rodent subjects. Radiat Res. 2007; 167: 12-42.

66. Shirodkar SP, Kishore TA, Soloway MS. The risk and prophylactic management of bladder cancer after various forms of radiotherapy. Curr Opin Urol. 2009; 19: 500-3.

67. Tubiana M. Can we reduce the incidence of second primary malignancies occurring after radiotherapy? A critical review. Radiother Oncol. 2009; 91: 4-15; discussion 1-3. 